\title{
Application of wavelet for seismic wave analysis in Kathmandu Valley after the 2015 Gorkha earthquake, Nepal
}

\author{
Binod Adhikari ${ }^{1,2^{*}}$, Subodh Dahal ${ }^{3}$, Monika Karki ${ }^{1}$, Roshan Kumar Mishra ${ }^{1}$, Ranjan Kumar Dahall, \\ Sudipta Sasmal ${ }^{5}$ and Virginia Klausner ${ }^{6}$
}

\begin{abstract}
In this paper, we estimate the seismogenic energy during the Nepal Earthquake (25 April 2015) and studied the ground motion time-frequency characteristics in Kathmandu valley. The idea to analyze time-frequency characteristic of seismogenic energy signal is based on wavelet transform which we employed here. Wavelet transform has been used as a powerful signal analysis tools in various fields like compression, time-frequency analysis, earthquake parameter determination, climate studies, etc. This technique is particularly suitable for non-stationary signal. It is well recognized that the earthquake ground motion is a non-stationary random process. In order to characterize a non-stationary random process, it is required immeasurable samples in the mathematical sense. The wavelet transformation procedures that we follow here helps in random analyses of linear and non-linear structural systems, which are subjected to earthquake ground motion. The manners of seismic ground motion are characterized through wavelet coefficients associated to these signals. Both continuous wavelet transform (CWT) and discrete wavelet transform (DWT) techniques are applied to study ground motion in Kathmandu Valley in horizontal and vertical directions. These techniques help to point out the long-period ground motion with site response. We found that the long-period ground motions have enough power for structural damage. Comparing both the horizontal and the vertical motion, we observed that the most of the high amplitude signals are associated with the vertical motion: the high energy is released in that direction. It is found that the seismic energy is damped soon after the main event; however the period of damping is different. This can be seen on DWT curve where square wavelet coefficient is high at the time of aftershock and the value decrease with time. In other words, it is mostly associated with the arrival of Rayleigh waves. We concluded that long-period ground motions should be studied by earthquake engineers in order to avoid structural damage during the earthquake. Hence, by using wavelet technique we can specify the vulnerability of seismically active region and local topological features out there.
\end{abstract}

Keywords: Wavelet analysis, Fast Fourier transform, Ground motion, 2015 Gorkha earthquake, Kathmandu Valley

\section{Introduction}

The over-stressed earth generates energy in the form of earthquake and volcanoes. Earthquake is a global phenomenon cause by unexpected fault rupture within the crust. This unexpected fault rupture results into sudden release of energy that stored in Earth's crust creating seismic waves (Ohnaka, 2013). The seismic activity states the frequency, type and size

\footnotetext{
* Correspondence: binod.adhi@gmail.com

${ }^{1}$ Department of Physics, St. Xavier's College, Maitighar, Kathmandu, Nepal

${ }^{2}$ Department of Physics, Patan Multiple Campus, Tribhuvan University, Patan

Gate, Lalitpur, Nepal

Full list of author information is available at the end of the article
}

of earthquakes experienced over an area for short period of time. Estimation of energy discharge during earthquakes is an elementary subject in geophysics. Charles Richter proposes an equation to compute the seismic wave energy from earthquakes (Gutenberg and Richter, 1942; Gutenberg and Richter, 1956). Usually, the seismic wave energy is estimated from the earthquake magnitude $M$ through the equation $\log E=1.5$ $\mathrm{M}+11.8$ proposed by Gutenberg and Richter (Gutenberg and Richter, 1956). Benioff (1951) initiated the studies of strain release. The same method, originally given by (Benioff, 1951), has been used by researchers for estimating energy released during earthquake. Besides, an older computation 
method has been followed for uniformity reason, although newer methods have been developed in the interim. Much estimation has been made by different researchers to predict seismic wave energy, for example (Gutenberg and Richter, 1942; Gutenberg and Richter, 1956; Bath, 1966; Vassiliou and Kanamori, 1982; Bolt, 1986; Kikuchi and Fukao, 1988 and Houston, 1990a, 1990b).

Earthquake ground motion signal have non-stationary amplitude and the energy associated with the signal is high at the beginning and decay at the end. The nonstationary frequency of seismic wave is associated with the time-frequency variation composition. This categorized different types of seismic waves at different time-instants and phenomenon of distribution. For non-stationarity in physical response has grabbed the attention of researchers. Most of the efforts were based on the work who proposed the concept of evolutionary power spectrum for slowly varying non-stationary process. This process is modeled by the product of a deterministic function and fixed method (Salajegheh and Heidari, 2002). Wavelet transformation is suitable application for studying the nonstationary signals at different frequencies. The wavelet analysis-continuous wavelet transform and discrete wavelet transform-applications are used in various fields like signal processing, compression, time- frequency study, earthquake parameter determination, and climate studies. Concept of wavelet was firstly introduced on 1980's for the analysis of seismic data, by Morlet et al. (1982) and Morlet (1983). This tool is also famous in applied geomagnetic seismology (Klausner et al., 2014a and Klausner et al., 2016a, Klausner et al., 2016b, Klausner et al., 2017). The amplitude of the wavelet coefficient can be used as a gauge of local uniformity of a signal as described in Mallat (1991). Heidari and Salajeghehb (2008) applied the wavelet transform to decompose the earthquake record of Taft (1952) and El Centro (1940). The types of wavelet transform vary with data and study goals (Domingues et al., 2005). This method is employed here to study the localized power variations within a time series.

\section{The $\mathbf{2 0 1 5}$ Gorkha earthquake}

The Gorkha (Nepal) earthquake 2015 is one of the tectonic earthquakes. There are four different types of natural earthquakes: Volcanic, Tectonic, Isostatic and Plutonic earthquakes. Among them the Tectonic earthquakes are common one. Gupta and Gupta (2010) mentioned that these occur when rocks in the earth's crust break due to geological forces created by tectonic plate movement. Different survey shows that Nepal is among the tectonically active regions of the world. The Himalayan region is tectonically active because of northward movement of the Indian Plate, and the repeated occurrence of the small magnitude earthquake. This point out that the Himalayas are under abnormally high stress and strain (Paudyal and Singh, 2008, Paudyal, 2008). The
Himalayan mountain region has been the point of some of the greatest continental earthquakes, including the Gorkha (Nepal) earthquake (Mw 8.1) happened on 25 April 2015 at 11:56 NST with an epicenter $28.147 \mathrm{~N}$ 84.708E of Kathmandu. This Gorkha earthquake affected not only Nepal, but also India, China and Bangladesh. This earthquake was among the powerful earthquakes to beat Nepal since 1934 (Nepal-Bihar earthquake Mw 8.1). The United Nation reported that 8 million people have been affected by 2015 earthquake in Nepal Ranjan (2015).

\section{Histogram for number of earthquakes}

From Fig. 1, it is seen that the maximum number of earthquakes occur in Dolakha, around 145.

Earthquakes. In comparison to other places, the minimum number of earthquakes occurs in Lamjung. There were around 30 earthquakes detected in Gorkha district including the 25 April 2015 magnitude Mw 8.1 at 11:56 local time. The earthquake modeled an unending risk by triggering numerous landslides, which caused major damage to settlements and infrastructure. The damages were mainly concentrated on districts like Dhading, Dolakha, Nuwakot, Rasuwa and Sindhupalchowk. Relatively, Sindhupalchowk area was highly affected. The landslide frequency is much higher on or near the crests of hills and mountains. An earthquake has great potential to induced geohazards through series of precarious processes, like landslides, avalanches with debris flow, landslide dams, and landslide dam outbursts (ICIMOD research report, 2016). The main induced geohazards caused by the 2015 Gorkha earthquake as mention in ICIMOD research report 2016 were landslides, river channel constriction and damming, and avalanches with debris flow and airburst. Earthquake-induced landslides were reported in Dhading, Gorkha, Rasuwa, and Sindhupalchok districts (Ranjan, 2015), where around 20, 30, 25 and 115 earthquakes were detected, respectively. In the Gorkha Earthquake, the landslides mainly occur in hilly districts lie at northern part of Kathmandu valley. The buildings on crests suffer more damage than those situated at the base. This is reported in Chautara town of Sidhupalchowk District. This is due to significant amplification of frequencies corresponding to wavelengths about equal to mountain width at hilltops with respect to the base (Geli et al., 1988). The cause of strong energy differential on the upper part of the slope is due to amplification-de-amplification pattern on slopes. In Langtang valley of Rasuwa districts, devastating avalanches are also reported after the April 25th earthquake. The detailed description on aftershock activity of the 2015 Nepal earthquake can found on Ichiyanagi et al. (2016).

\section{Distribution of earthquake with longitude and latitude}

Figure 2 shows the earthquake distribution map and $2 \mathrm{D}$ plot which clearly shows that the maximum 


\section{No. of earthquake}

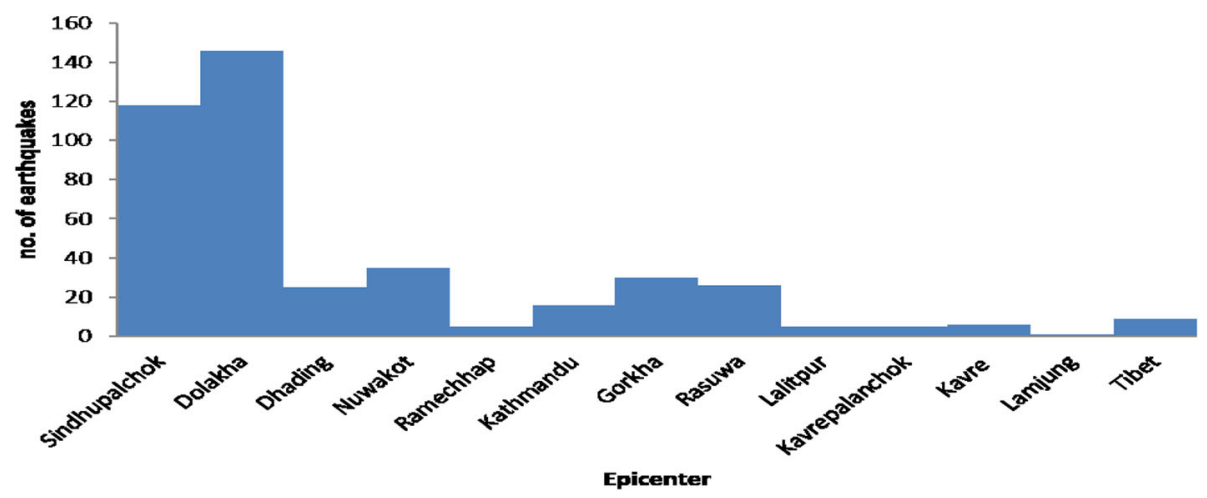

Fig. 1 Histogram of number of aftershock events occurred in different districts of Nepal after Gorkha, Nepal Earthquake 25 April 2015

number of earthquake occurred within latitude $28^{\circ} \mathrm{N}$ to $30^{\circ} \mathrm{N}$ and longitude is $80^{\circ} \mathrm{E}$ to $90^{\circ} \mathrm{E}$ which is the location around Kathmandu valley within around 80 $\mathrm{km}$ radius. In the figure, spot signifies the location where as the number represent earthquake magnitude in Mw. It can be observed that the maximum latitude of Barpak VDC (Village Development Committee) of Gorkha Nepal Earthquake is $28.60 \mathrm{~N}$ and the maximum longitude is $86.6 \mathrm{oE}$, which lies $80 \mathrm{Km} \mathrm{NW}$ from the capital city, Kathmandu. The epicenter was at Barpak VDC. The main shock was followed by many aftershocks. Many of the large aftershocks occurred to the east of themain shock which is denoted by dots on map. There are 421 aftershocks with a magnitude $\mathrm{Mw}$ 4. Four aftershocks had a magnitude Mw 6.0, including main shock of magnitude, Mw 7.6 with epicenter in Sindhupalchok district after the first big earthquake. The earthquake occurred as a result of faulting confined to the subsurface which was approximately $15 \mathrm{Km}$ deep near the bottoms of the Himalayan range (Ichiyanagi et al., 2016, Duputel et al., 2016 and ICIMOD research report, 2016/1).

\section{Dataset}

The data recorded by the station TVU (Central Department of Geology, Tribhuvan University), THM

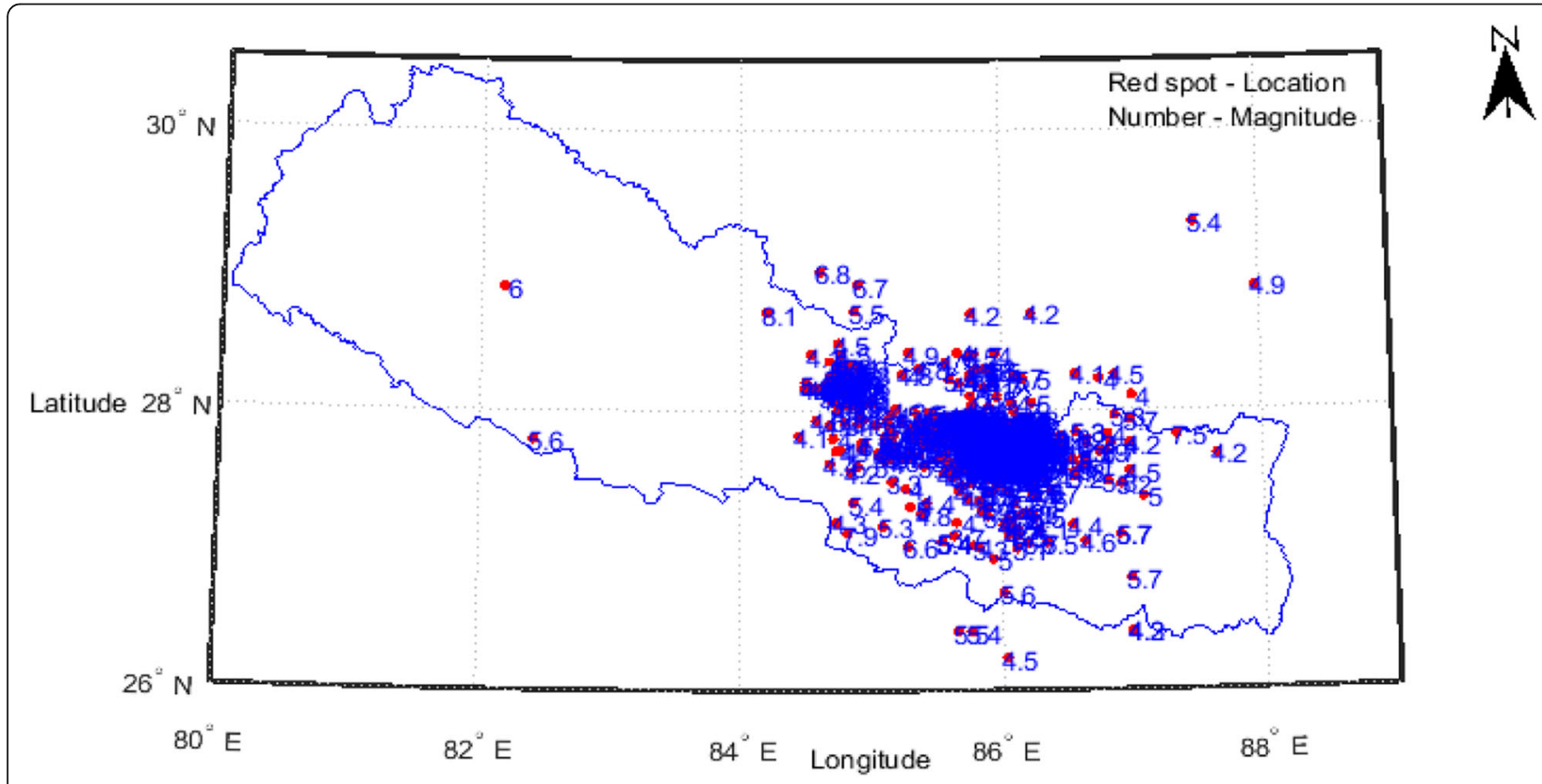

Fig. 2 Earthquake distribution map representing magnitude, location, latitude degree and longitude degree of Nepal earthquake 2015 
(University Grants Commission office, Bhaktapur), KTP (Kirtipur Municipality Office) and PTN (Institute of Engineering, Pulchowk Campus, Patan) during Gorkha Nepal Earthquake of 25 April 2015(a large tectonic earthquake) are used in our study to know the better results. These stations are located inside the Kathmandu Valley and their building are RC 2F i.e. reinforced concrete frame (model 2). It has an infilled shear wall in the central frame (Model 2). The Valley has a growing population, uncontrolled development, and unmanaged construction practice that has actually degraded over this century. Like many urban areas in developing countries, Kathmandu Valley's risk has increased significantly since the last major earthquake. According to Mugnier et al. (2011) the earthquake's effects were amplified in Kathmandu Basin-contains up to $600 \mathrm{~m}$ of sedimentary rocks- representing the infilling of a lake. So we are interested to study ground motion during earthquake inside the Kathmandu Valley and try to locate high risk areas. By using GPS, we can measure ground motion from large tectonic earthquakes because rocks on either side of a fault are offset during this type of earthquake. Nepal lacks a thick accelerometers network; however, the USGS has established a station (KATNP) that records earthquakes in Kathmandu. In our project datasets from this station are also analyzed (see Fig. 3).

The detail about the stations can be found on Table 1 (Miyake et al., 2017). The high data quality recorded during Gorkha Nepal Earthquake of 25 April 2015 earthquake at various places motivate to know its various features and to find new technique. The energy liberated from other earthquakes and their magnitudes are used for the testing of the methodology.

The epicenters of around 30,000 earthquakes are now reports annually by the International Seismological Center. Earthquakes epicenters are not uniformly distributed over the surface of earth. So, the epicenters location and the recorded data are considered in our analysis. Only, earthquake epicenters from different places with magnitude $\mathrm{Mw} 8.2$ are considered in this study. Earthquake events from Gorkha, Sindhupalchok, Lalitpur, Dolakha, Nuwakot, and Kavrepalanchok are taken into account during the study.

\section{Methodolog}

The CWT (Continuous Wavelet Transform) provides detailed information of a signal in terms of time and scale (Adhikari, 2015). The windowed Fourier Transform was reconstructed and established the CWT by Grossmann and Morlet (1984). The CWT is an integral transform which can quantity the time-frequency variation as discussed by Klausner et al. (2013). The CWT method can be implemented as the alternative path to address issues such as data availability and its quality, database error points, and gaps. Klausner et al. (2013) discussed it in more details. Mathematically, CWT function $f(t)$ can be written as.

$$
w(a, b)=\int \mathrm{f}(\mathrm{t}) \phi *\left(\frac{t-b}{a}\right) d t
$$

Where, $\phi *$ signifies the complex conjugate, and 'a' and ' $\mathrm{b}$ ' are dilation and translation parameters, respectively. The W (a, b) function represents the wavelet

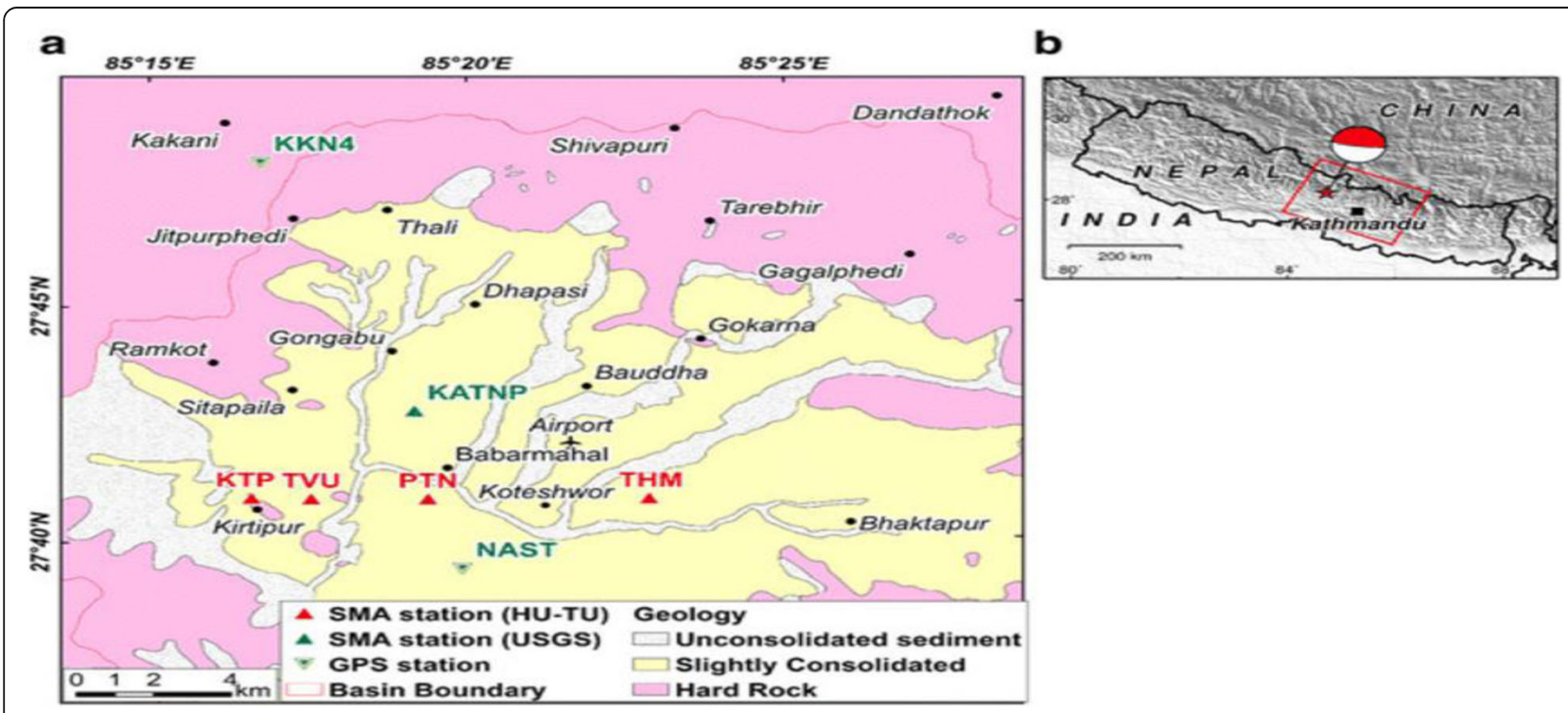

Fig. 3 "a" and "b" shows Kathmandu Basin as well as the location of strong-motion seismometers (Shrestha, et al. 1999) 
Table 1 Station code and their location information. Station Code Latitude Longitude Height (m) Building Type

\begin{tabular}{lllllll}
\hline Station Code & Latitude & Longitude & Height $(\mathrm{m})$ & Building Type & $\begin{array}{l}\text { Epicentral Distance } \\
(\mathrm{Km})\end{array}$ \\
\hline TVU & & & & Base \\
THM & N27.68179 & E85.28825 & 1320 & RC 2F & 77.0 & soil \\
KTP & N27.68130 & E85.37705 & 1320 & RC 3F & 83.7 & soil \\
PTN & N27.68216 & E85.27259 & 1370 & RC 4F & 75.9 & Rock \\
\hline
\end{tabular}

coefficients. We applied this wavelet transform, because it is good for localizing simultaneously time and frequency. With this in hands, we can analyze the low and high frequency and time period characteristics of the signal.

On other hand, the DWT (Discrete Wavelet Transform) is square integral functional linear

mul-tiscale transform deals with non -stationary signals. This helps to observe local regularity present in the signal (Klausner et al., 2014b, 2016b). This tool also decomposes the signal into distinctive frequency variation and acquire information localized in both frequency and space domain. This technique is used as alternative way to analyze seismogenic and tsunamigenic impact on the geomagnetic field (Klausner et al., 2014a, 2016a, 2016b). It develops visual inspection tough task which construct the wavelet function that depends upon the scale function. Here, the 2nd order Daubechies orthogonal wavelet is chosen. Mathematically, DWT Wavelet coefficient can written as

$$
\mathrm{d}_{\mathrm{k}}^{\mathrm{j}}=2^{-\mathrm{j} / 2} \int f(t) \phi\left(2^{j} t-k\right)
$$

The coefficients djk is known as details (details are higher frequency structures).

\section{Result and discussion}

In this section, we discuss the ground motions (aftershocks) of gorkha earthquake 2015 using wavelet analysis (both CWT and DWT). Wavelet based analysis obviously ameliorate our understanding of this events deeply. It relates energy bursts to seismic wave arrivals. The analysis performed here is mainly focused on CWT and DWT. CWT and DWT based techniques are two possible approaches to improve the clarity of wavelet analysis which is addressed below. Gurley and Kareem (1999) presented numerous ex- amples citing the wavelet analysis usefulness in the identification and characterization of transient random processes involving in ocean engineering, wind and earthquakes. It involves spectral and co-spectral analysis for transient events identification, non-stationary signals simulation, and noisy signals filtration.

\section{Ground motion analysis}

In order to develop the seismic hazard assessment and its mitigation, it is necessary to improve our understanding over ground motion produced by earthquake. In Figs. 4, 5, 6 and 7, the analysis of the strong ground motion characteristics of devastating earthquake after the aftershock events observed on the site TVU, THM, KTP, and PTN respectively are presented. The data used in this paper include the ground acceleration data collected at sampling rate of $100 \mathrm{HZ}$ during an aftershock event occurred on 25 April 2015. The time scale in seconds and ground acceleration in $\mathrm{cm} / \mathrm{s}^{2}$ are present in horizontal and vertical axis respectively Strong ground motion can be observed in Kathmandu valley. The peak ground acceleration $(\mathrm{PGA})>250 \mathrm{~cm} / \mathrm{s}^{2}$ was recorded on the EW component at the site TVU and KTP for the after- shock occurred on 06:35 UTC (25 April 2015). At this site the PGA of NS component and vertical component was 100 $\mathrm{cm} / \mathrm{s}^{2}$. Due to such high ground motion within Kirtipur(location of TVU and KTP station) area building are severely damaged/partially collapsed. Damage to these buildings is mainly due to the decline of material strength, lack of repair, maintenance and strengthening works. Soil amplification occurs typical to laquestrine and deep clay deposits like in Kathmandu valley. The PGA was around $150 \mathrm{~cm} / \mathrm{s} 2$ recorded at the site THM on EW and whereas the vertical component was around $120 \mathrm{~cm} / \mathrm{s} 2$ peak amplitude of the NS component. At PTN site the PGA recorded on EW, NS and vertical component was around $120 \mathrm{~cm} / \mathrm{s}^{2}$. The large value of PGA was by reason of isolated shock waves from the origin time. From Figs. 5, 6, 7 and 8, it can be observed that horizontal long duration oscillation with large amplitude at each site. These observation is shore up with the result found by Takai et al. (2016) for Nepal earthquake. Kumar et al. (2016) studied ground motion of Nepal earthquake occurred on 25 April 2015 using the data from sites (one rock site and three sedimentary sites). They found that the largest PGA was $241 \mathrm{~cm} / \mathrm{s}^{2}$ recorded on the EW component at the rock site and that on horizontal component was $250 \mathrm{~cm} / \mathrm{s} 2$. They also use USGS data to calculate the ground acceleration and found the value around 0.02 to $0.74 \mathrm{~g}$. The Boorea et al. (2008) equations predict PGA of $0.49 \mathrm{~g}$ for the Mw7.8. Goda et al. (2015) inspect time-history data recorded at 

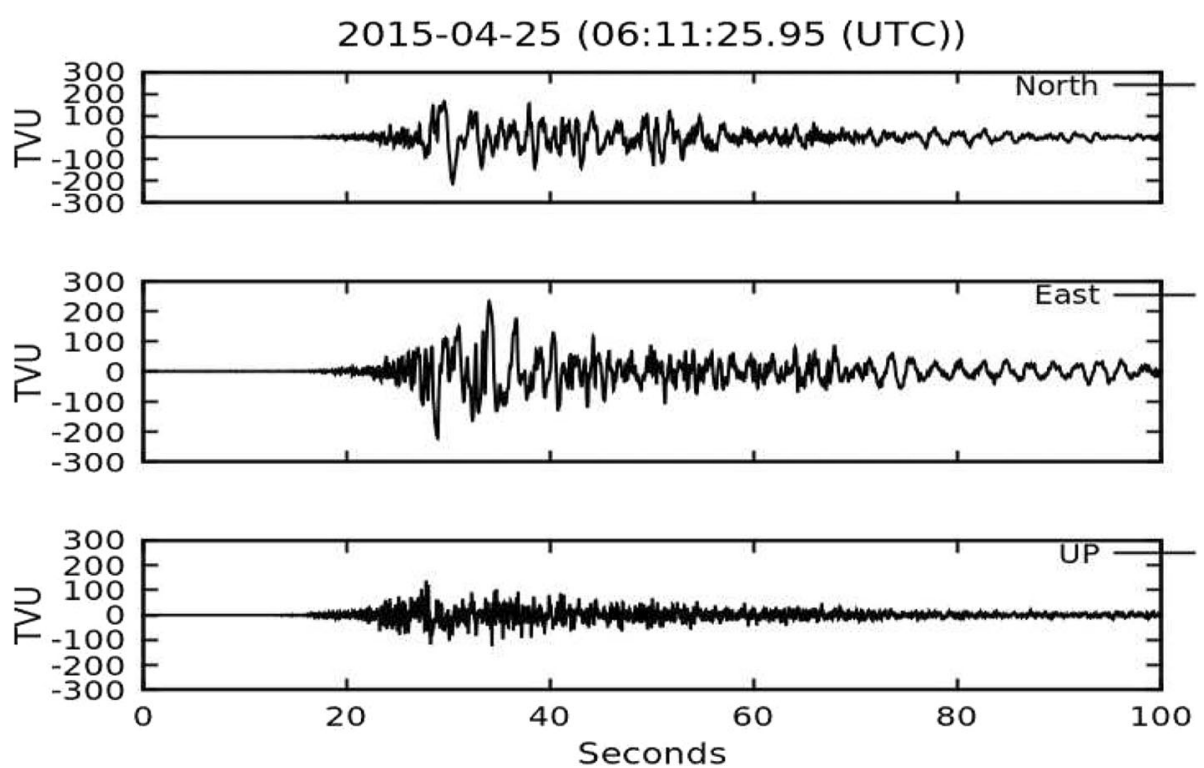

Fig. 4 Ground acceleration waveform recorded at station TVU. The $x$-axis and $y$-axis represents time scale in seconds and ground acceleration in $\mathrm{cm} / \mathrm{s}^{2}$ respectively

KATNP. They mentioned that the PGA for Mw 7.8 main shock and the Mw 7.6 aftershock event is about $150-170$ and $70-80 \mathrm{~cm} / \mathrm{s}^{2}$ respectively. According to United States Geological Survey USGS (2015) the fault size of the Gorkha earthquake was around $200 \mathrm{~km}$ long and $150 \mathrm{~km}$ wide. According to ICIMOD research report, $2016 / 1$ the fracture transmitted $150 \mathrm{~km}$ to the east and $60 \mathrm{~km}$ to the south of Barpak VDC. In case of large earthquake, the epicentral distance alone is not an effective parameter for ground motion determination because large affected area lies directly within the rupture zone. S-waves arrives at a given
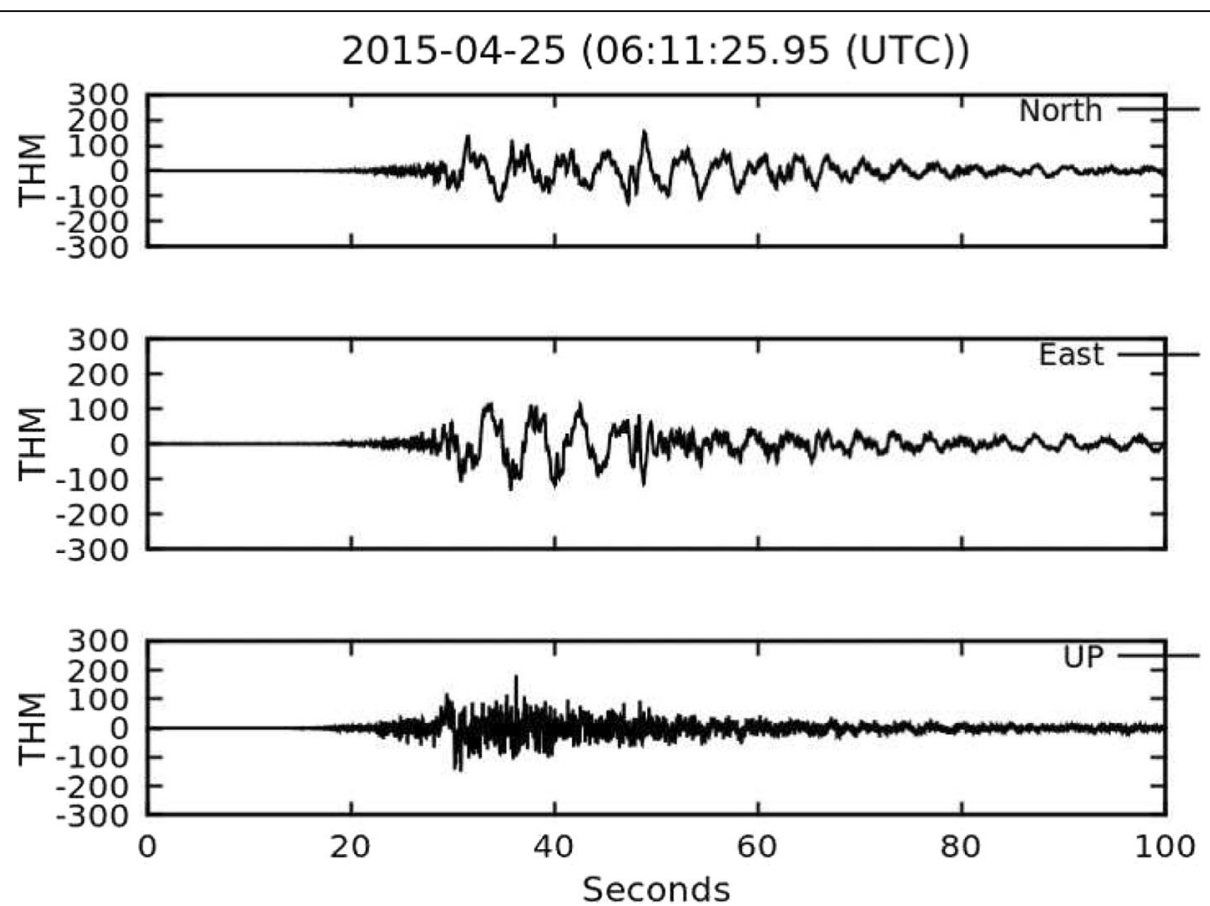

Fig. 5 Ground acceleration waveform recorded at station THM. The x-axis and $y$-axis represents time scale in seconds and ground acceleration in $\mathrm{cm} / \mathrm{s}^{2}$ respectively 

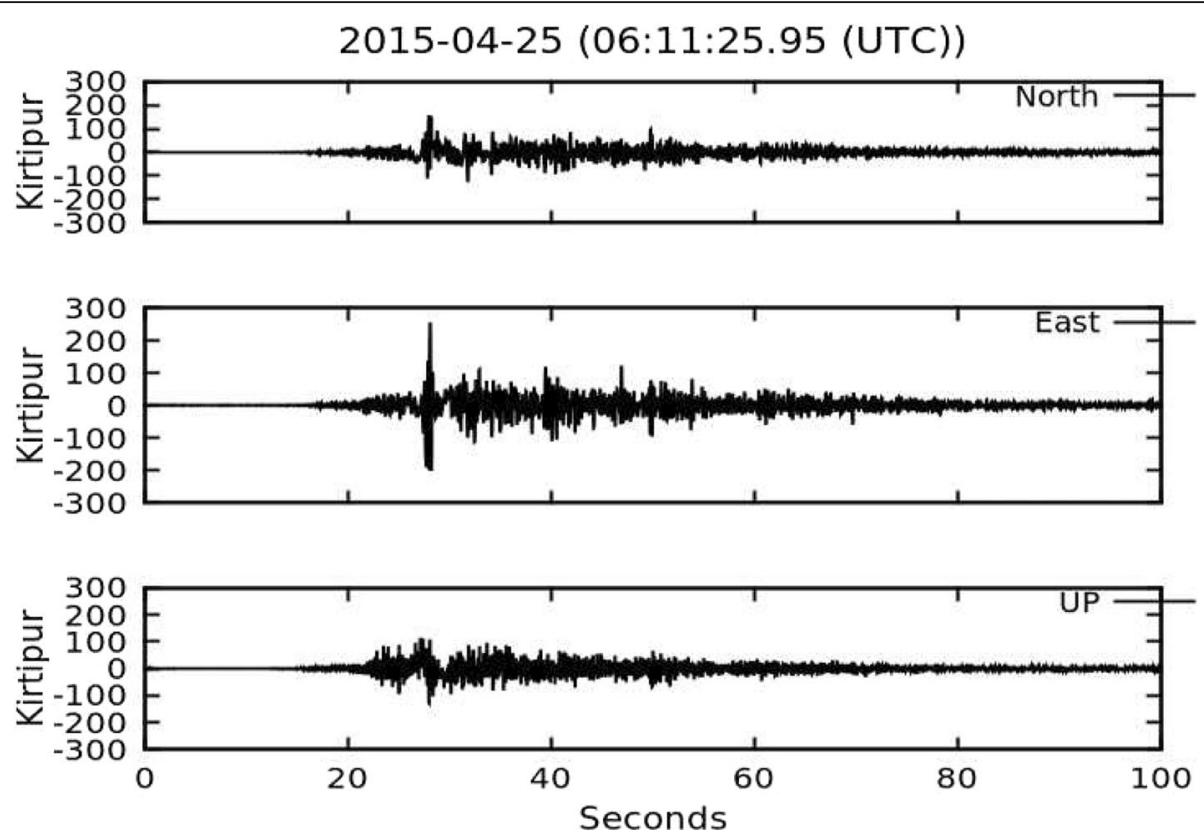

Fig. 6 Ground acceleration waveform recorded at station KTP. The $x$-axis and $y$-axis represents time scale in seconds and ground acceleration in $\mathrm{cm} / \mathrm{s}^{2}$ respectively

point not just come from the epicenter but arrives as a whole from rupture zone. Previously, researcher used multifactor approach for time-frequency analysis of non-stationary ground motion (Kameda, 1975; Scherer, 1994). Researchers Hui Cao and Ming Lai (200, in their paper proved that the LPS (local power spectra) of the process estimated by wavelet transform describe its non-stationary characteristics accurately and the LPS transfer has enough precision to reflect the time-frequency characteristics of earthquake ground motions. They showed that results obtained by non-stationary methods are bigger than those by
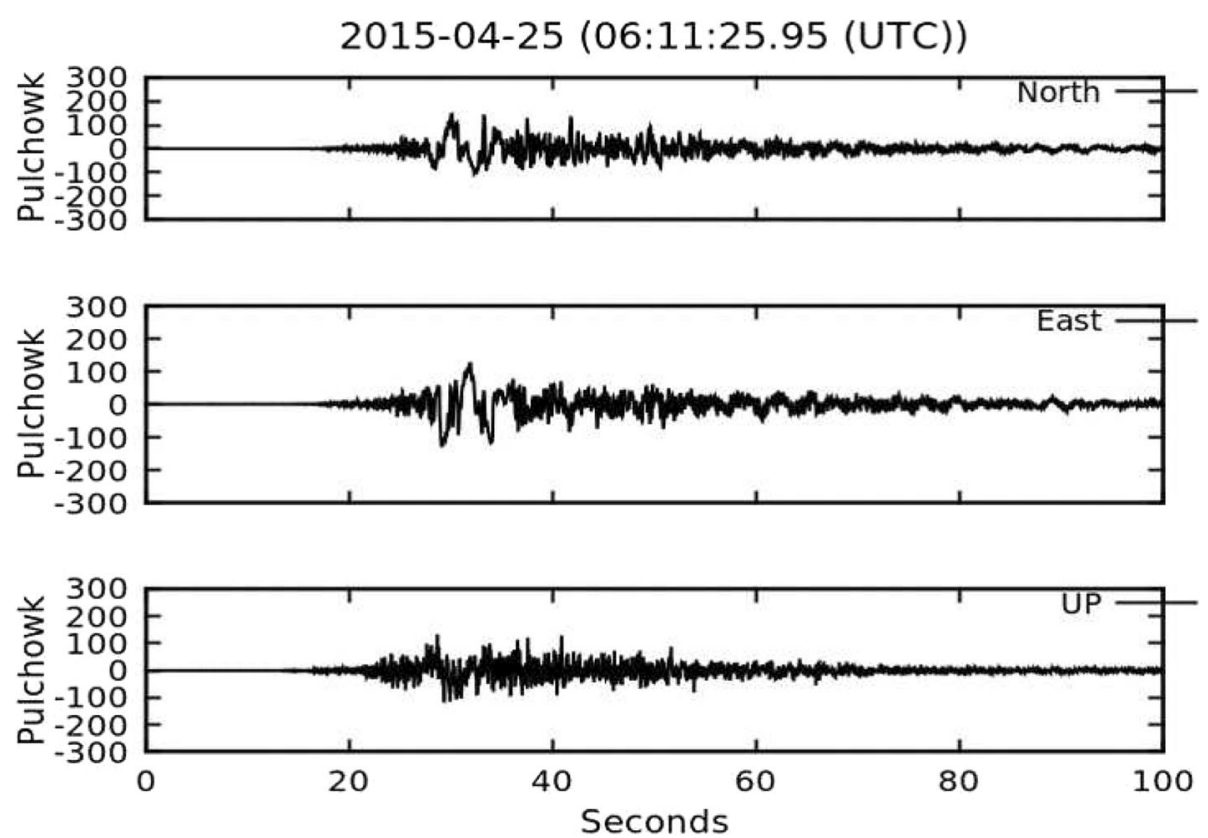

Fig. 7 Ground acceleration waveform recorded at station PTN. The x-axis and $y$-axis represents time scale in seconds and ground acceleration in $\mathrm{cm} / \mathrm{s}^{2}$ respectively 

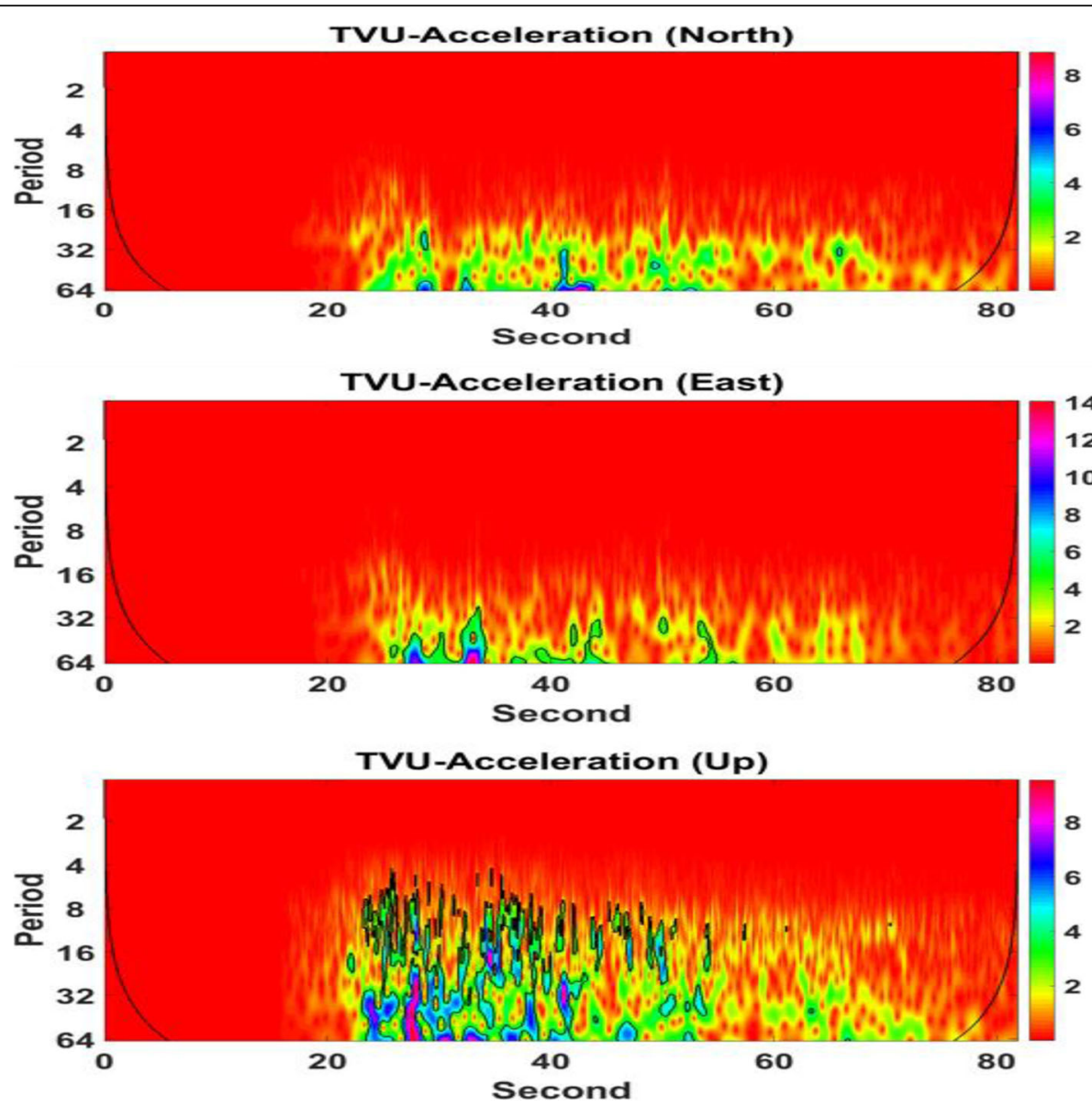

Fig. 8 Two Dimension CWT-Scalogram ground motion from NS, EW, and Vertical record (0-80 s) at TVU station

stationary methods which are in accordant with the conclusions of Wu (1989).

\section{CWT analysis}

Figs. 8, 9, 10 and 11 display the result of CWT. This analysis helps to understand the patterns relative to seismic events occurred on 25 April 2015 Nepal. These figures show a time-frequency sketch of ground motion noted by TVU, THM, KTP and PTN stations, respectively. In these figures, the horizontal axis denotes the time scale and the vertical axis denotes the period. In these figures, it is possible to represent the energy distributions of signal in both frequency and time, and also, to analyze some specific aspects. The first aspect is to equate the amplitude amplification by discontinuities that exist in the signal and another is to observe sudden changes. The after-shock event starts at 06:11:25.95 UTC (25 April 2015). The occurrence of energy bursts at different times can be noted in the time history easily. These figures demonstrates the existence of multi scale feature of the signal. And also shows how the energy transference is taking place. These characteristics give the impression on the scalogram through the scattering of frequencies. The color scale present on the right side of the panel has same unit of real data. In the scalogram, stronger wavelet power areas are displayed as pink and the lower wavelet power areas are displayed as red. The scalogram of NS, EW and vertical motion shows different highest intensity power areas displayed as pink color and blue color. By comparing Figs. 8, 9, 10, and 11 it is observed that there is a clear power area for 30 s i.e., there is clear ground motion during the earthquake within this time. Similarly, within this time the less intense power areas are seen at many places covered by green and blue color. In Fig. 8, we can observe long duration horizontal motion with large frequency during the earthquake. There is a pink, blue and green band in between the period range of $64-32(0.015-0.031 \mathrm{~Hz})$ seconds for NS and EW ground motion while those bands observed in the period range of 64-8 (0.015$0.125 \mathrm{~Hz}$ ) second for vertical motion. In other words, this range of period is the most remarkable for all constructions which have the same frequency as the 

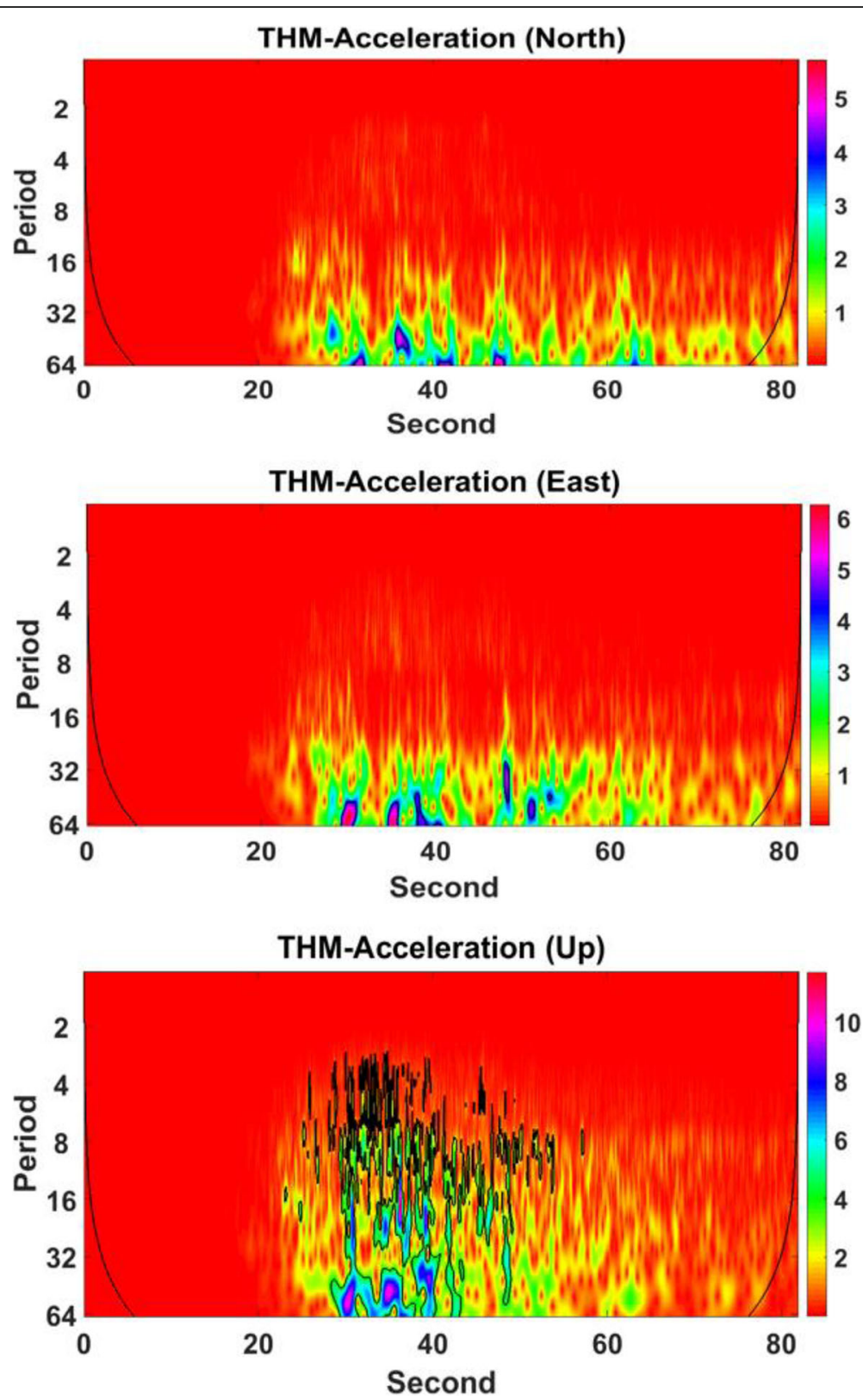

Fig. 9 Two Dimension CWT-Scalogram ground motion from NS, EW, and Vertical record (0-80 s) at THM station

foremost frequency of earthquake. The nature and power areas in Fig. 10 are similar to Fig. 9. In Fig. 11, there is pink, blue and green band of power area around period 64-16 $(0.015-0.0625 \mathrm{~Hz})$ seconds for NS and EW ground motion while those bands observed in the period range of $64-8(0.015-0.125 \mathrm{~Hz})$ second for vertical motion. In Fig. 11 the nature of scalogram is similar to that of Fig. 10. By comparing Figs. 8, 9, 10, and 11 it is also observed that the effect of motion starts from around 06:11:31UTC to 06:11:51UTC. Similarly, in Fig. 10, the energy burst of the highest peak amplitude with period approximately 32-16 (0.031-
$0.0625 \mathrm{~Hz}$ ) around the time 06:11:35UTC. The maximum wavelet power area has intensity around 23 unit as shown in Fig. 11 for EW scalogram. By comparing Figs. 8, 9, 10, and 11 it is also observed that the highest frequency spectrum of ground motion record in horizontal scalogram.

The less intense areas are seen at the comparative scales for every interval of each component. This suggests that the periodicity is constantly communicating throughout the earthquake. Also we see that the zone with less periodicity occur frequently and the zone with the high periodicity occur less frequently. This is exactly 

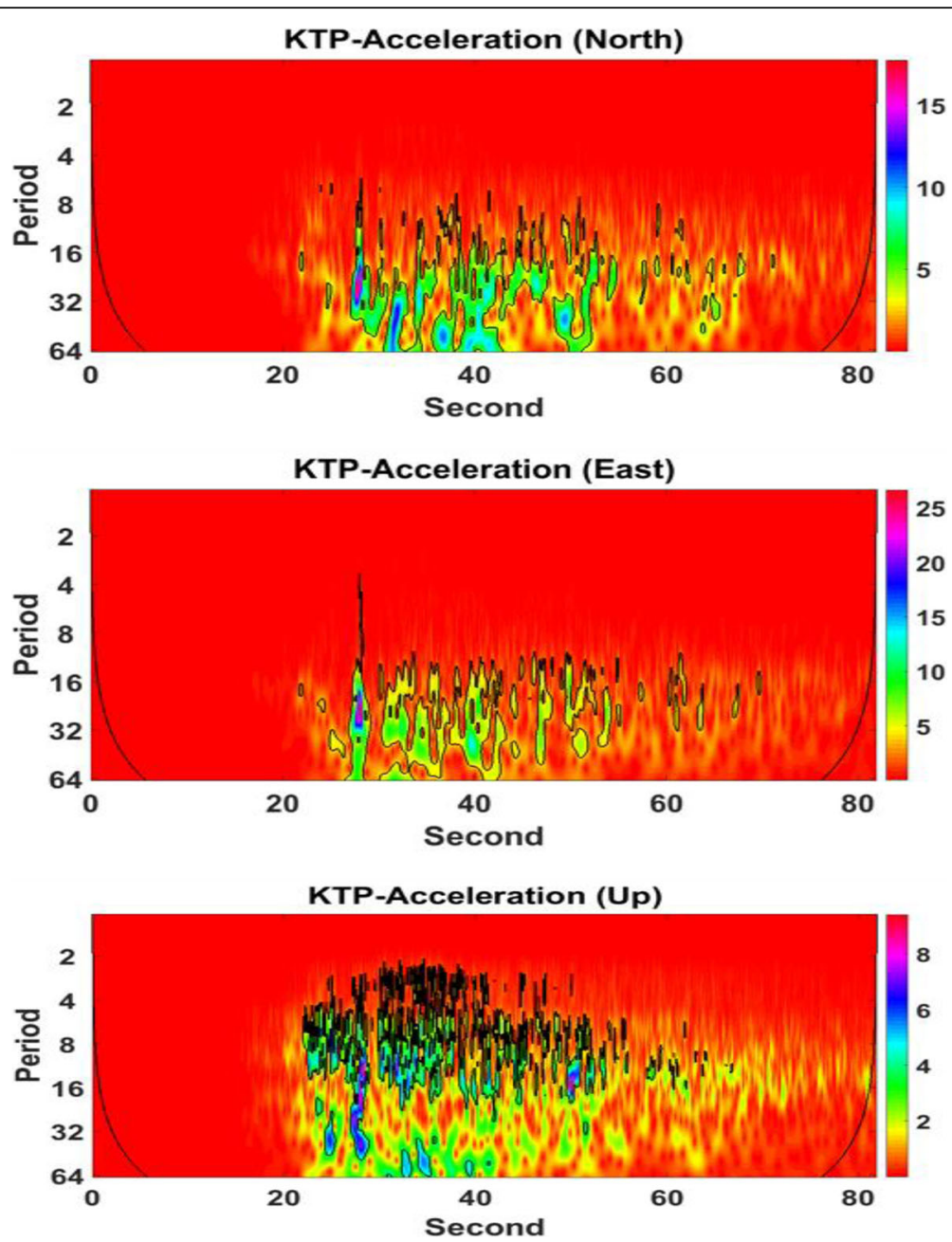

Fig. 10 Two Dimension CWT-Scalogram ground motion from NS, EW, and Vertical record (0-80 s) at KTP station

in accordance with the frequency periodicity inverse relation i.e. the high frequency components with less periodicity and high intensity are found to lie within period range $64-32 \mathrm{~s}(0.015-0.031 \mathrm{~Hz})$. And hence we can infer that any construction with natural frequencies lying within this frequency band or close enough to this have high chances to suffer the resonance and get destroyed. Thus we found CWT to be good tool to study the nature of seismic waves.

\section{DWT analysis}

Figures 12, 13, 14 and 15 illustrates the results obtained from DWT analysis. Daubechies, (1992) define this wavelet transform as a mathematical tool which helps to filter signals into different frequency components. So that we can analyze each component with its resolution accorded to scale. It is used for dynamic analysis of structures tempted by earthquake loading (Salajegheh and Heidari, 2002; Salajegheh and Heidari, 2005; Heidari and Salajegheh, 2006) and optimize the structural analysis (Salajegheh and Heidari, 2004a; Salajegheh and Heidari, 2004b; Salajegheh et al., 2005). Gurley and Kareem (1999) used this method for modeling, analysis, and simulation of non-stationary processes by decomposing random processes into localized orthogonal basis functions. In this paper, we used second order Daubechies orthogonal wavelet transform of level $j=1$ and 2 . The optimize description of second order Daubechies orthogonal wavelet transform can be found in (Domingues et al., 2005; Gonz'alez et al., 2014; Klausner et al., 2014b, Adhikari and Chapagain, 2016, Adhikari et al., 2017). Actually wavelet transformation determines how a chain of wavelet functions characterize the signal. The wavelet transformation results consist different order coefficients allied with two independent variables, dilation and translation. The scale is a process of analyzing the frequency contents, while translation typically represents time. The main steps involve are to calculate and analyze the wavelet coefficients of one decomposition levels, and to select the wavelet coefficient thresholds that allows to detect 


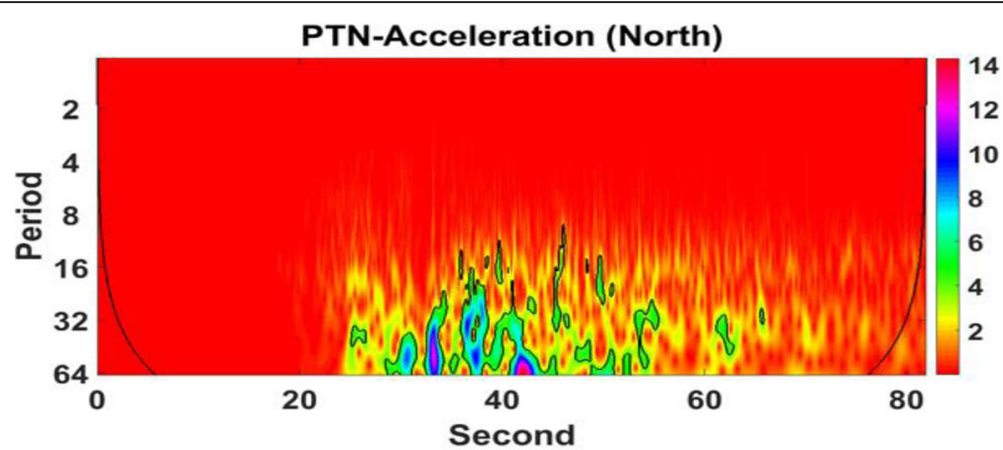

PTN-Acceleration (East)

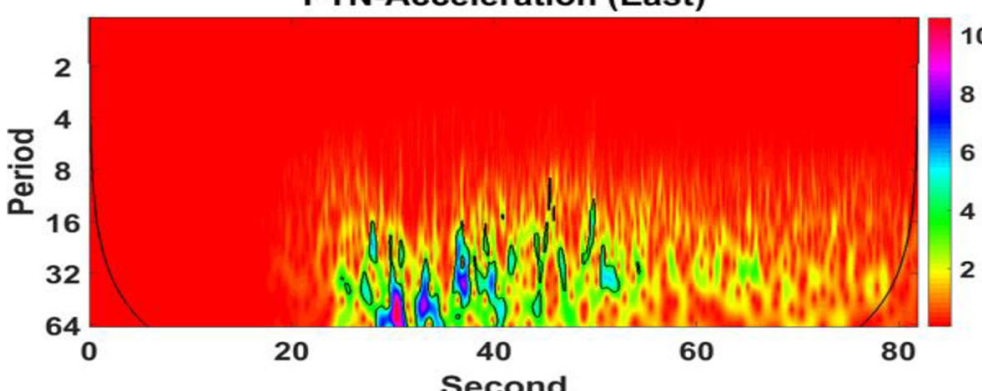

PTN-Acceleration (Up)

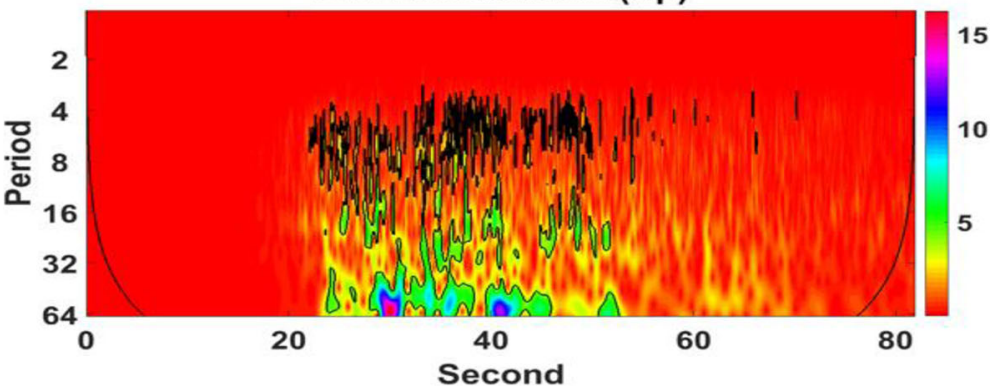

Fig. 11 Two Dimension CWT-Scalogram ground motion from NS, EW, and Vertical record (0-80 s) at PTN station

singularity present in the earthquake ground motion signal. In those figures the time interval of data sampling is $0.005 \mathrm{~s}$ but the recorded data length varies for each event. For this study, record length of $81.92 \mathrm{~s}(16,384=$ 214 samples) is picked. The discrete wavelet transform require samples of power 2 for calculation.

Figures 12, 13, 14 and 15 show the behavior of Daubechies wavelet coefficients d (for $j=1$ and 2 ) of ground motion signal during aftershock events that occurred on 25 April 2015. The wavelet coefficients versus the corresponding wavelet time with detail sub bands (d1and d2) are plotted in those figures. The frequency bands for each sub band are specified for ideal filters. To avoid Gibbs effect, the actual filters decay slowly across the ideal bands which results into some partial overlap between these intervals. Therefore, the wavelet map indicates the position (both in time and frequency) of the wavelets used for approximation. By the Perceval equality, the square of those wavelet coefficients would give the analogous term in the series of signal energy. Such a map indicates energy distribution of the signal on time-frequency plane. For visual comparison, the original signals is shown at the top of each figures. The principle behind the use of amplitude of wavelet coefficients is to symbolize the local regularity present in the signal (Mallat, 1989; Domingues et al., 2005; Ojeda et al., 2011, Gonz'alez et al., 2014, Adhikari and Chapagain, 2016, Adhikari et al., 2017). The peak amplitudes of wavelet coefficients point out significant fluctuation of signal. The resulting singularity patterns is equivalent with the sudden energy release in the Earth's crust.

This generates seismic waves on the fault slip surface. By comparing Figs. 12, 13, 14 and 15, it is observed that there is no effect of ground motion up to $18 \mathrm{~s}$. The effect of ground motion starts from $20 \mathrm{~s}$ to $80 \mathrm{~s}$ with higher and lower amplitude discontinuously. In Figs. 12, 13, 14 and 15 we can observe several peaks of different amplitude in lower order frequency but in higher order frequency we can observe significant fluctuation. Here in Fig. 12, square wavelet coefficients show several high amplitude peaks 


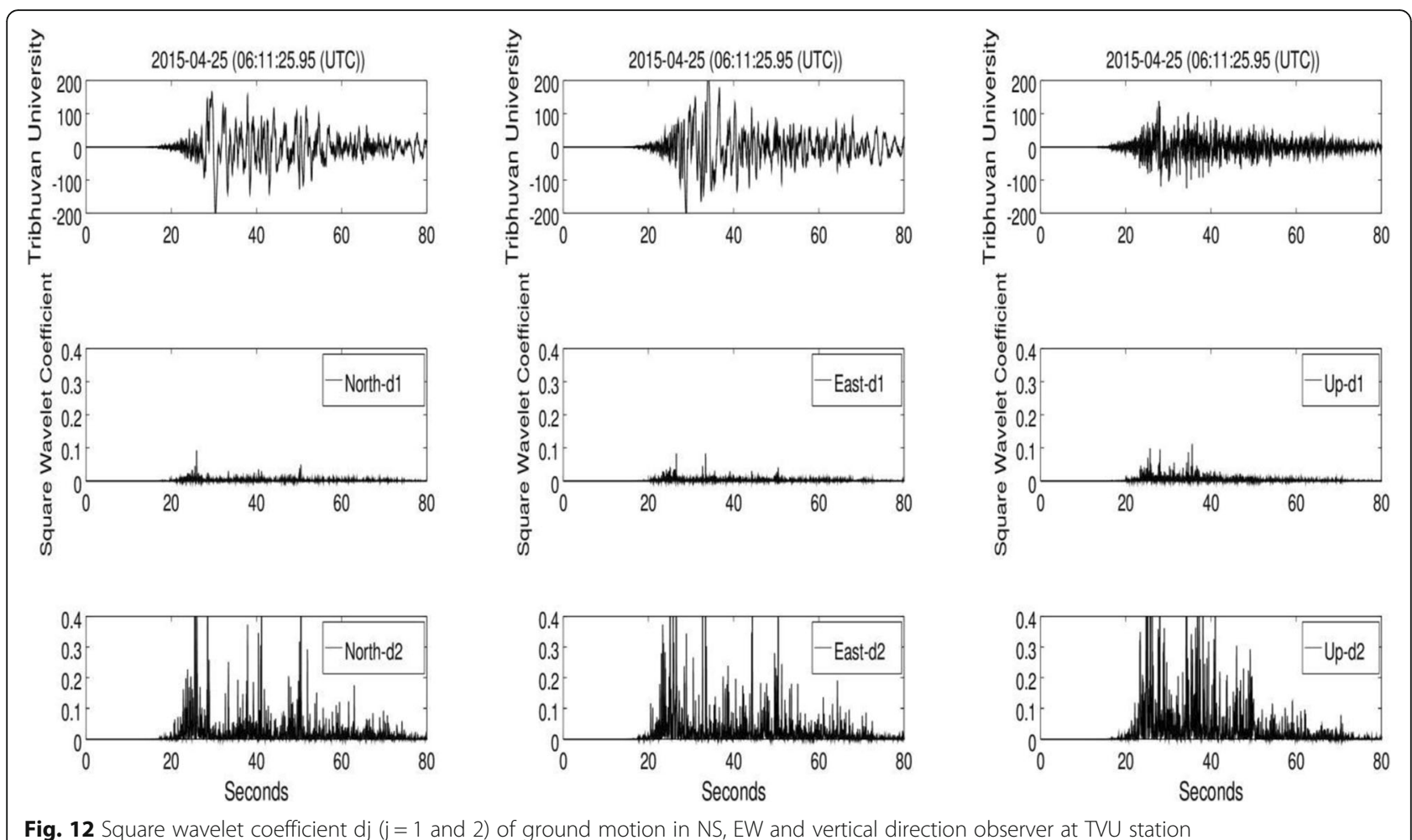

Fig. 12 Square wavelet coefficient $d j(j=1$ and 2 ) of ground motion in NS, EW and vertical direction observer at TVU station

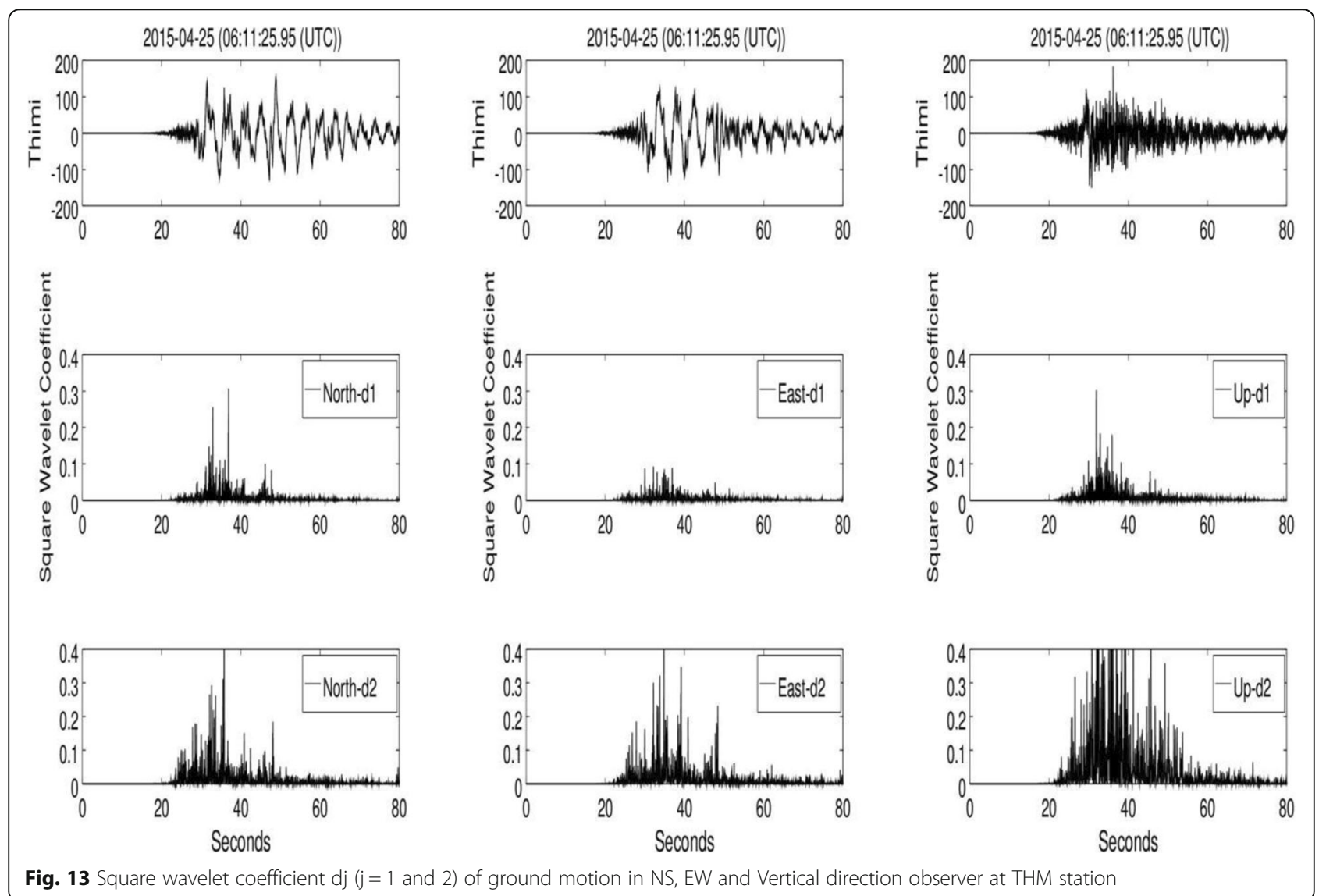



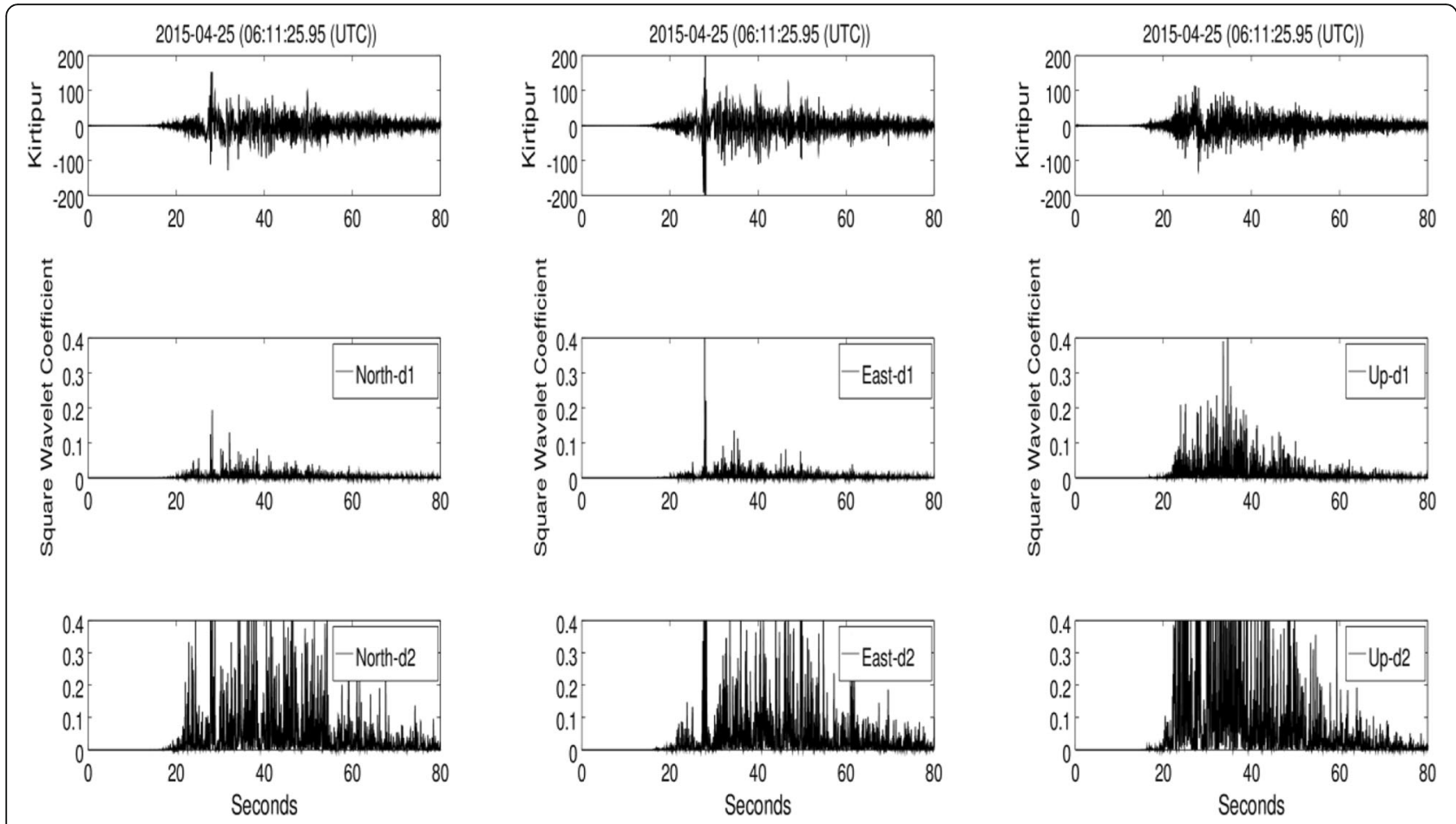

Fig. 14 Square wavelet coefficient dj $(j=1$ and 2) of ground motion in NS, EW and Vertical direction observer at KTP station

corresponds to vertical ground motion while peaks corresponds to NS and EW ground motion are of lower amplitude. In Fig. 13, several sharp peaks for vertical ground motion at the time of aftershock. Here some sharp peaks are also seen for NS and EW ground motion but the amplitude is lower than that of Vertical ground motion. In Fig. 14, singularity peaks of high amplitude can be found in all direction ground motion signal but number of such peak is high for vertical ground motion signal.

In Fig. 15 also, number of singularity peaks of high amplitude found on vertical ground motion signal. We can say that NS, EW and vertical motion as observed by four different stations where singularity present in signals observed during peak of aftershock. Moreover, it can be noticed in all figures that the highest wavelet coefficient amplitudes seems to be associated with the Rayleigh wave arrival. The rupture directivity and fling step effects might be two crucial factors for the strong ground motion observed in Kathmandu valley. The rupture directivity is also a key factor causing the large ground motion during the Gorkha earthquake (Koketsu et al., 2016). Comparing NS, EW and Vertical motion, most of the high amplitude signals are associated with vertical motion, because in that direction energy release is high. These sudden variations accounts for the high destruction caused due to the Earthquake. Similarly from all panels we see that the singularity follows the pattern of transference of energy. The small amplitudes observed in the wavelet coefficients for the Earthquake means the energy transfer process is smooth; while the larger amplitudes indicate that there are impulsive energy injections superimposed to smooth background process. This transference of the energy even supports for the cause of destruction.

Soon after the main event seismic energy damped but the period of damping is different. This can be seen on DWT curve where square wavelet coefficient is high at the time of aftershock and the coefficient decrease with time. The damping period depends upon the types of site i.e. sedimentary or rock site. At rock site seismic energy highly damped. For each case, it is observed that in the higher-frequency sub bands signal has less energy. This is important to most of the coefficients in these sub bands which is being eliminated by the thresholding. In those plots the low-amplitude high frequency pulses are curved in low approximation levels, while the largest amplitude pulses are still signified quite well. This is the characteristic of data compression by thresholding. By this process the high-frequency components are sieved where they are small and are well-preserved, and where they are significant. From CWT analysis, the high frequency components with less periodicity and high intensity power areas are found to lie between time 20-80 s. It is interesting to found singularity-at the same time-on the signal from DWT graph. 


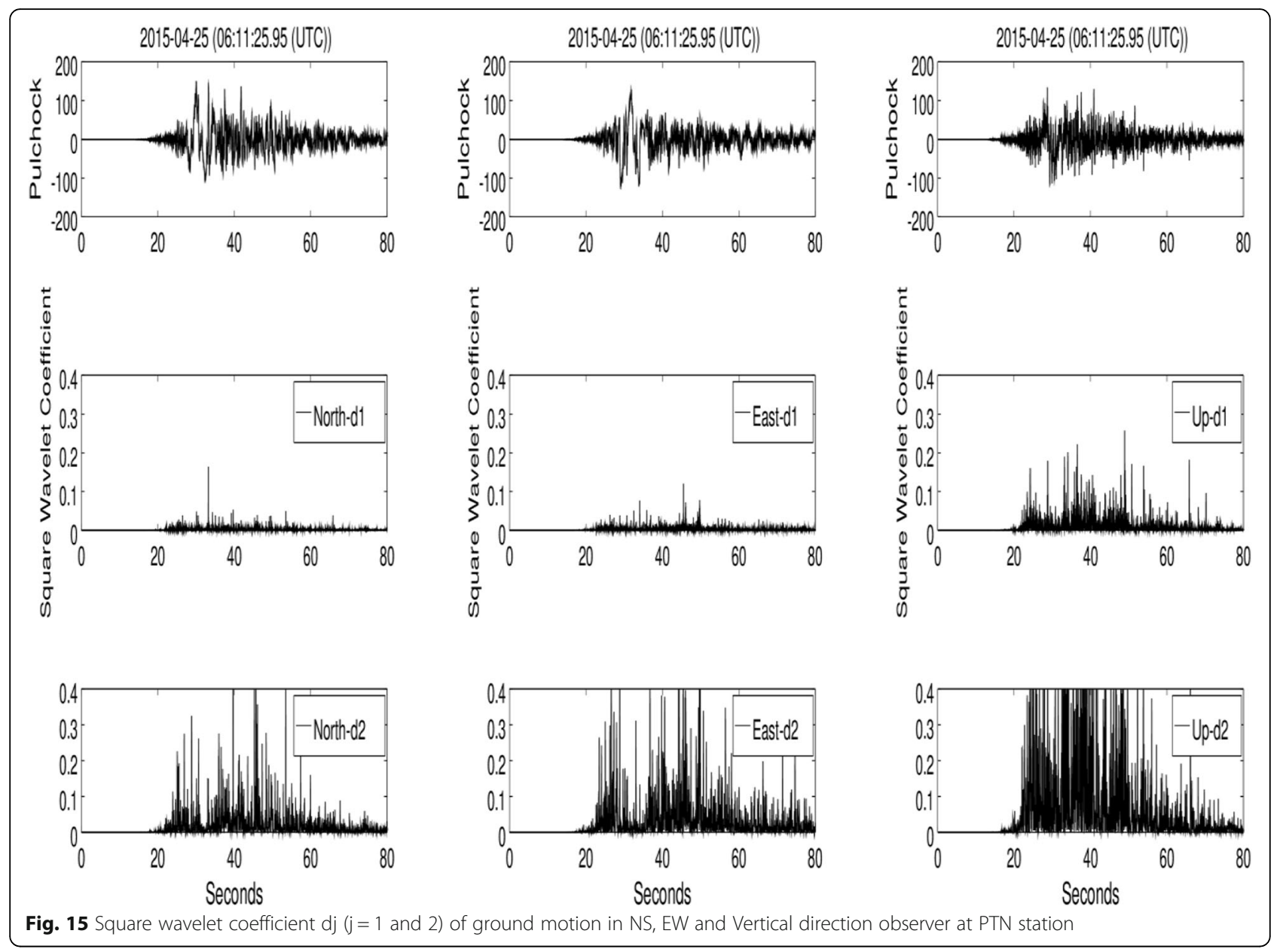

From these figures we can see the two level decomposition are sufficient to notice the singularity patterns. Taking the fact that the highest amplitude of the wavelet coefficients indicate singularities, in all cases singularity patterns were identified associated with the intense earthquake effect. When the ground motion is under less intense condition i.e. times where motion was comparatively low the accelerations value recorded in the seismograms can be represented by the smooth functions, and the wavelet coefficients show low amplitude accordingly. As the Earthquake had the moment magnitude around 8.3 we certainly expected to see highest amplitudes at most places and indeed we can see it at level d1. In other words we can say that DWT or those coefficients are able to identify sudden variations in ground motion that occurred during Earthquake. The wavelet coefficients of two levels i.e. first and second decomposition level of the wavelet transform show indeed a better time localization and then are locally associated with the higher frequencies during the Earthquake. Thus in our case we concluded that the decomposition levels has proven to be sufficient to isolate the singularity patterns. In each components and for all the decomposition levels we can see the transient variations which are almost similar; the only difference is maximum value of amplitude. This value is slightly different in each case and the reason behind may also be the orientation or the direction the seismic wave that is being recorded in the seismogram. Thus using DWT in earthquake analysis can provide us with different advantages. This can give us the good view of the sudden variations occurring during the Earthquake. The singularity patterns can show us the positions of occurrence of higher frequency components which in our case were almost entirely distributed for the considered interval. This can also show how the energy transference takes place during the phenomenon.

\section{Conclusion}

This paper concisely presents the advantage of the seismic applications of wavelet techniques. The main objective behind the use of these techniques is to expose the hidden characteristics of the original signal, and also, to analyze it more effectively. These technique are used to study the ground motion in Kathmandu valley. The Kathmandu valley, where basin consist thick lacustrine soft sediments, is one of the seismically active region. 
The buildings in Kathmandu valley are haphazardly constructed and do not follow the seismic design standards which specify the seismic vulnerability of Kathmandu valley. We apply both the CWT and the DWT techniques to study the ground motion in Kathmandu Valley in NS, EW, and vertical directions. Comparing NS, EW and vertical motion, most of the high amplitude signals are associated with the horizontal motion because of high energy is released in that direction. The DWT square wavelet coefficients are higher at the time of aftershock, and their values decrease with time after it. The damping period depends upon the types of site i.e. sedimentary or rock site. At the rock sites, seismic energy is highly damped. At the rock site of Kathmandu valley, the amplified acceleration pulses on the EW and NS components are found. At the sedimentary sites of Kathmandu valley, horizontal ground acceleration was prolonged as compared with the rock site. This is due to the thick soft sediments that deposited at the basin of Kathmandu valley. Hence, the multistory buildings without seismic design at sedimentary sites had highest chance of damage. We found that the main causes of severe structural damage and collapse of buildings in Kathmandu are due to the large peak in the short range ground acceleration. We pointed out that some multistory buildings in Kathmandu were remain unaffected by the long-period ground motions because of nonresonance. We concluded that long-period ground motions should be studied by earthquake engineers in order to avoid structural damage during the earthquake. Wavelet analysis shows that the signals having high frequency components are for short duration and low frequency components are for long durations. It also shows that the low-amplitude high frequency pulses are curved in low approximation levels, while the largest amplitude pulses are still signified quite well. Singularity observed during the peak of aftershock associated in the ground motion signal tells about the direction of seismic wave energy release. It is concluded that the wavelet transform is a potent analytical tool to recognize the features of input motion in both time and frequency and to understand the factors associated with long-period response of seismic vulnerable site based on the three dimensional acceleration structure. This oversees the dynamic behavior of constructions and their protection. Finally, it is concluded that the local topological features may contribute to extensive damage in Kathmandu valley.

\footnotetext{
Abbreviations

CWT: Continuous Wavelet Transform; DWT: Discrete Wavelet Transform; EMSC: European-Mediterranean Seismological Centre; EW: East West; FFT: Fast Fourier Transform; ICIMOD: International Centre for Integrated Mountain Development; KATNP: strong-motion seismograph station Kantipath; KTP: Kirtipur Municipility Office, Kirtipur; LPS: local power spectra; Mw: Moment magnitude; NST: Nepal Standard Time; PGA: Peak ground acceleration; PTN: Pulchowk Campus, Institute of Engineering, Tribhuvan
}

University, Patan; RC F2: Reinforced Concrete Frame 2; THM: University Grants Commission office, Sanothimi, Bhaktapur; TVU: Central Department of Geology, Tribhuvan University, Kirtipur; USGS: United State Geological Survay; UTC: Coordinated Universal Time NS=North South; VDC: Village

Development Committee NW=North West

\section{Acknowledgements}

The datasets were obtain from European-Mediterranean Seismological Centre (EMSC) wave page: http://www.emsc-csem.org/Earthquake/seismologist.php, Central Department of Geology, Tribhuvan University, University Grants Commission office, Bhaktapur, Kirtipur Municipility Office and Pulchowk Campus, Institute of Engineering, Patan. And the dataset downloaded from the web page:[http://www.strongmotioncenter.org] is for the study of ground motion and from webpage [http://www.emsc-csem.org/Earthquake/ seismologist.php] is for the study of energy released. We would like to thanks for them.

\section{Authors' contributions}

$\mathrm{BA}=\mathrm{He}$ developed the idea of this manuscript. He has major contribution to prepare introduction, dataset and methodology and conclusions. SD $=\mathrm{He}$ has major contribution on introduction as well as Result and discussion. MK= Few plots have been developed. RKM $=$ He has contribution on dataset and methodology section. RKD $=$ He gave overall feedback on this manuscript. He reviewed throughly and added local topological features of Nepal and damages causes after gorkha earthquake 2015. SS= He also gave overall feedback on this manuscript. He reviewed throughly and gave a shape of complete manuscript. VK = She has contribution on wavelet Analysis. Both CWT and dwt analysis were reviewed thoroughly.

\section{Funding}

Not Applicable

\section{Availability of data and materials}

The data recorded by the station TVU (Central Department of Geology, Tribhuvan University), THM (University Grants Commission office, Bhaktapur), KTP (Kirtipur Municipality Office) and PTN (Institute of Engineering, Pulchowk Campus, Patan) during Gorkha Nepal Earthquake of 25 April 2015(a large tectonic earthquake) are used in our study to know the better results. These stations are located inside the Kathmandu Valley

\section{Competing interests}

The authors declare that they have no competing interests.

\section{Author details}

${ }^{1}$ Department of Physics, St. Xavier's College, Maitighar, Kathmandu, Nepal. ${ }^{2}$ Department of Physics, Patan Multiple Campus, Tribhuvan University, Patan Gate, Lalitpur, Nepal. ${ }^{3}$ Department of Physics, Himalayan College of Geomagnetic Engineering and Land Resource Management, Kathmandu, Nepal. ${ }^{4}$ Geodisaster Research Center, Central Department of Geology, Tribhuvan University, Kirtipur, Kathmandu, Nepal. ${ }^{5}$ Indian Centre for Space Physics, Kolkata, India. ${ }^{6}$ Department of Physic and Astronomy, Vale do Paraiba University, Sao Jose dos Campos, SP, Brazil.

Received: 21 May 2019 Accepted: 16 October 2019

Published online: 06 January 2020

\section{References}

Adhikari B (2015) HILDCAA-realted effects recorded in middle -low latitude magnetometer, PhD thesis, Instituto Nacional de Pesquisas Espaciais. (INPE)

Adhikari B, Chapagain NP (2016) Polar cap potential and merging electric field during high intensity long duration continuous auroral activity. J Nepal Phys Soc 3(1):6-17

Adhikari B, Khatiwada R, Chapagain NP (2017) Analysis of geomagnetic storms using wavelet trans-forms. J Nepal Phys Soc 4(1):119-124

Bath M (1996) Earthquake energy and magnitude in contribution in Geophysics, In Honor of Beno Gutenberg, eds, Benioff, M.E, Howell, B.F and Press, Pergamon, Press, New York.

Benioff H (1951) Earthquakes and rock creep :( part l: creep characteristics of rocks and the origin of aftershocks). Bull Seismol Soc Am 41(1):31-62

Bolt, B. A. (1986). Seismic energy release over a broad frequency band. pure and applied geophysics, 124(4), 919-930 
Boorea D, Atkinson G (2008) Ground-Motion prediction equations for the average horizontal component of PGA, PGV, and 5\% damped PSA at spectral periods between $0.01 \mathrm{~s}$ and $10.0 \mathrm{~s}$. Earthquake Spectra - EARTHQ SPECTRA. 24. https://doi.org/10.1193/1.2830434

Domingues MO, Mendes O, da Costa AM (2005) On wavelet techniques in atmospheric sciences. Adv Space Res 35(5):831-842

Duputel Z, Vergne J, Rivera L, Wittlinger G, Farra V, Hetnyi G (2016) The 2015 Gorkha earthquake: a large event illuminating the Main Himalayan thrust fault. Geophys Res Lett 43(6):2517-2525

Geli L, Bard PY, Jullien B (1988) The effect of topography on earthquake ground motion: a review and new results. Bull Seismol Soc Am 78(1):42-63

Goda K, Kiyota T, Pokhrel RM, Chiaro G, Katagiri T, Sharma K, Wilkinson S (2015) The 2015 Gorkha Nepal Earthquake: Insights from Earthquake Damage Survey. Frontiers in Built Environment 1(8):1-15. https://www.frontiersin.org/ article/10.3389/fbuil.2015.00008.

Gonz'alez AO, Junior OM, Menconi VE, Domingues MO (2014) Daubechies wavelet coefficients: a tool to study interplanetary magnetic field fluctuations. Geofsica Internacional 53(2):101-115

Grossmann A, Morlet J (1984) Decomposition of hardy functions into square integrable wavelets of constant shape. SIAM J Math Anal 15(4):723-736

Gupta BL, Gupta A (2010) Principles of earthquake resistant Design of Structures and Tsunami

Gurley K, Kareem A (1999) Applications of wavelet transforms in earthquake, wind and ocean engineering. Eng Struct 21(2):149-167

Gutenberg B, Richter CF (1942) Earthquake magnitude, intensity, energy, and acceleration. Bull Seismol Soc Am 32(3):163-191

Gutenberg B, Richter CF (1956) Earthquake magnitude, intensity, energy, and acceleration (second paper). Bull Seismol Soc Am 46(2):105-145

Heidari A, Salajegheh E (2006) Time history analysis of structures for earthquake loading by wavelet networks. Asian J Struct Eng 7:155-168

Heidari A, Salajeghehb E (2008) Wavelet analysis for processing of earthquake records. Asian J Civ Eng 9(5):513-524

Houston H (1990a) Broadband source spectrum, seismic energy, and stress drop of the 1989 Macquarie ridge earthquake. Geophys Res Lett 17(7): $1021-1024$

Houston H (1990b) A comparison of broadband source spectra, seismic energies, and stress drops of the 1989 Loma Prieta and 1988 Armenian earthquakes. Geophys Res Lett 17(9):1413-1416

Ichiyanagi M, Takai N, Shigefuji M, Bijukchhen S, Sasatani T, Rajaure S et al (2016) Aftershock activity of the 2015 Gorkha, Nepal, earthquake determined using the Kathmandu strong motion seis- mographic array. Earth Planets Space 68(1):25

Kameda H (1975) Evolutionary spectra of seismogram by multifilter. J Eng Mech Div 101(6):787-801

Kikuchi M, Fukao Y (1988) Seismic wave energy inferred from long-period body wave inversion. Bull Seismol Soc Am 78(5):1707-1724

Klausner V, Kherani EA, Muella MTAH (2016) Near- and far-field tsunamigenic effects on the $Z$ component of the geomagnetic field during the Japanese event, 2011. J Geophys Res. Space Physics 121:1772- 779. https://doi.org/10. 1002/2015JA022173

Klausner V, Almeida T, de Meneses FC, Kherani EA, Pillat VG, Muella MTAH, Fagundes PR (2017) First report on Seismogenic magnetic disturbances over Brazilian sector, pure Appl. Geophys 174:1772-1779. https://doi.org/10.1007/ s00024-016-1455-0

Klausner V, Gonz'alez AO, Domingues MO, Mendes O, Papa ARR (2014b) Study of local regularities in solar wind data and ground magnetograms. J Atmos Sol Terr Phys 112:10-19

Klausner V, Kherani EA, Muella MT (2016a) Nearand farfield tsunamigenic effects on the Z component of the geomagnetic field during the Japanese event, 2011. J Geophys Res Space Physics 121(2):1772-1779

Klausner V, Mendes O, Domingues MO, Papa AR, Tyler RH, Frick P, Kherani EA (2014a) Advantage of wavelet technique to highlight the observed geomagnetic perturbations linked to the Chilean tsunami (2010). J Geophys Res Space Physics 119(4):3077-3093

Klausner V, Papa AR, Mendes O, Domingues MO, Frick P (2013) Characteristics of solar diurnal variations: A case study based on records from the ground magnetic station at Vassouras, Brazil. J Atmos Sol Terr Phys 92:124-136

Klausner V, Papa ARR, Cndido CMN, Domingues MO, Mendes O (2016b) An alternative way to identify local geomagnetically quiet days:a case study using wavelet analysis. Ann. Geophys., European Geosciences Union 34:451462
Koketsu K, Miyake H, Guo Y, Kobayashi H, Masuda T, Davuluri S et al (2016) Widespread ground motion distribution caused by rupture directivity during the 2015 Gorkha, Nepal earthquake. Sci Rep 6:28536

Kumar A, Singh MD, Roy LS (2016) Field evidence of Gorkha earthquake of 25 April (7.8 M) and Kodari earthquake of 12 May 2015 (7.2 M) in Nepal. Geomatics Nat Hazards Risk:1-15. https://doi.org/10.1080/19475705.2016. 1181677

Mallat S (1991) Multiresolution approximations and wavelets orthonormal bases. Trans Am Math Soc 315:334351

Miyake H, Sapkota SN, Upreti BN et al. (2017) Special issue "The 2015 Gorkha, Nepal, earthquake and Himalayan studies: First results". Earth Planets Space 69, 12. https://doi.org/10.1186/s40623-016-0597-8.

Morlet J (1983) Sampling theory and wave propagation. Issues in Acoustic signal/ Image processing and recog- nition, vol 1, pp 233-261

Morlet J, Arens G, Fourgeau E, Glard D (1982) Wave propagation and sampling theoryPart I: complex signal and scattering in multilayered media. Geophysics 47(2):203-221

Mugnier JL, Huyghe P, Gajurel AP, Upreti BN, Jouanne F (2011) Seismites in the Kathmandu basin and seismic hazard in central Himalaya. Tectonophysics 509(1):33-49

Ohnaka M (2013) The physics of rock failure and earthquakes. Cambridge University Press. https://doi.org/10.1017/CBO9781139342865

Ojeda GA, Mendes O, Domingues MO (2011) A WAVELET TOOL TO IDENTIFY THE OCCURRENCE OF INTERPLANETARY MAGNETIC CLOUDS: PRELIMINARY RESULTS. In: Conferncia Brasileira de Dinmica, Controle e Aplicaes (Vol. 1, No. nico, pp. 707-710). SBMAC

Paudyal H (2008) Seismicity and seismotectonics of Nepal and its adjoining region (doctoral dissertation, Ph. D. Thesis submitted to Banaras Hindu University, Varanasi, India (unpublished))

Paudyal H, Singh HN (2008) Seismicity of Nepal Himalaya and its adjoining regions: recent perspective. J. Sci Res 52:19-31

Ranjan KD (2015) Engineering Geological Issues after Gorkha Earthquake 2015 in Nepal: a preliminary understanding 10th Asian Regional Conference of IAEG 2015

Salajegheh E, Heidari A (2002) Dynamic analysis of structures against earthquake by combined wavelet transform and fast Fourier transform. Asian J Civ Eng 3 : $75-87$

Salajegheh E, Heidari A (2004a) Optimum design of structures against earthquake by adaptive genetic algorithm using wavelet networks. Struct Multidiscip Optim 28:277-285

Salajegheh E, Heidari A (2004b) Optimum design of structures against earthquake by wavelet transforms and filter banks. Int J Earthquake Eng Struct Dynamics 34:67-82

Salajegheh E, Heidari A (2005) Time history dynamic analysis of structures using filter banks and wavelet transforms. Comput Struct 83(1):53-68

Salajegheh E, Heidari A, Saryazdi S (2005) Optimum designs of structures against earthquake by a modified genetic algorithm using discrete wavelet transform. Int J Numer Methods Eng 62:2178-2192

Scherer RJ (1994) On the frequency dependence of the strong ground motion duration, structural safety and reliability, Schueller, Shinozuka and Yao (eds.). Balkema Publishers, Rotterdam, pp 2201-2223

Shrestha OM, Koirala A, Hanisch J, Busch K, Kerntke M, Jäger S (1999) A geoenvironmental map for the sustainable development of the Kathmandu Valley, Nepal. GeoJournal 49(2):165-172

Takai N, Shigefuji M, Rajaure S, Bijukchhen S, Ichiyanagi M, Dhital MR, Sasatani T-t (2016) Strong ground motion in the Kathmandu Valley during the 2015 Gorkha. Nepal Earthquake Earth Planets Space 68:10. https://doi.org/10.1186/ s40623-016-0383-7

Vassiliou MS, Kanamori H (1982) The energy release in earthquakes. Int J Seismological Soc Am 72(2):371-387

Wu WF (1989) Envelope crossing rate and first passage probability. ASCE, pp $1271-1278$

\section{Publisher's Note}

Springer Nature remains neutral with regard to jurisdictional claims in published maps and institutional affiliations. 